\title{
Pathophysiology of Stress-Induced Limbic Lobe Dysfunction: A Hypothesis for NDEs
}

\author{
Daniel Carr \\ Massachusetts General Hospital \\ Boston, Massachusetts
}

\begin{abstract}
Near-death experiences (NDEs) bear a strong resemblance to complex hallucinations associated with limbic lobe dysfunction. To date, no convincing explanation of the pathogenesis of NDEs has been presented, but the recent recognition of endogenous opioid peptides has provoked speculation that secretion of such neurohormones may be related to the placidity and analgesia observed early in NDEs. The present paper reviews electrophysiological data (not cited, to the author's knowledge, in the thanatologic literature) in support of a novel hypothesis that endorphins and enkephalins along with other centrally active peptide neurohormones may, by virtue of their capacity to provoke hippocampal neuronal activity, trigger the characteristic limbic lobe syndrome of NDEs and hence produce a constellation of effects in addition to passivity and anesthesia. Because there is ample evidence to suggest that the metabolism of neurohormones undergoes disruption both centrally and peripherally during precisely those sorts of stress in which NDEs typically occur, it is plausible that such behaviorally active peptides are the long sought-after "endogenous hallucinogens" of agonal states.
\end{abstract}

\section{INTRODUCTION}

In recent years considerable interest has arisen in cataloging patients' reactions in many instances of near death (Ring, 1982). From this work has emerged recognition of a strikingly uniform pattern of psychological responses during many such episodes involving individuals of varied ethnic, cultural, religious, and racial backgrounds (Moody, 1975; Osis and Haraldsson, 1977). Indeed, an argument may be made that the uniformity of near-death experiences (NDEs), particularly their noetic quality (Noyes and Kletti, 1976; Stevenson and Greyson, 1979), may have contributed to the formation of parallel religious beliefs in widely separated cultures (Aries, 1981). While certain parallels have been drawn between NDEs and subjective responses to well-characterized stimuli such as anesthesia or hypercarbia (Meduna, 1950), a unitary explanation of 
NDEs in physiological terms has not yet been accomplished. The purpose of the present paper is to describe a novel, plausible pathophysiological mechanism to account for the occurrence of NDEs during stress.

\section{NDE as Neurologic Syndrome}

The vividness of NDEs is frequently felt by their experients to be evidence of their reality, and to distinguish NDEs from hallucinations. Yet the clinical literature on hallucinations clearly distinguishes between real and pseudo-hallucinations, the former having the character of objectivity and the latter having the character of subjectivity (Keup, 1970; Siegel and West, 1975). A complementary formulation regards absence or presence of insight as the most important difference between real and pseudo-hallucinations (Hare, 1973). A recent review of complex hallucinations points out that both subcortical and allocortical structures are likely to be involved in the production of these phenomena (Trimble, 1981). Thus, the vividness of NDEs need not be taken as proof of their reality, but rather may be viewed as a clinical clue helping to suggest the particular brain structures in which dysfunction occurs.

The latter view, that analysis of NDEs in neurological terms may permit identification of malfunctioning brain regions, is not novel. Indeed, several authors have expressed the view that NDEs are symptoms of limbic lobe dysfunction, in that many features of NDEs (depersonalization, involuntary memory recall, intense emotions such as euphoria, and auditory, visual, or kinetic hallucinations) are present in cases of hyperactivity of limbic lobe neurons (Moody, 1975; Ring, 1980; Rodin, 1981; Sabom, 1982; Siegel, 1981). The hyperactivity of limbic lobe neurons giving rise to clinical symptoms resembling NDEs may be spontaneous, as in temporal lobe epilepsy (Merritt, 1973) or iatrogenic, as in cases of electrical brain stimulation (West, 1962; Penfield and Perot, 1963).

Emerging evidence supports the view that limbic lobe neuronal hyperactivity may arise as a consequence of local action of endogenous peptide hormones during times of physical stress (Nicoll et al, 1977; Urca et al, 1977; Frenk et al, 1978a, 1978b; Henriksen et al, 1978). Because the latter observations are key to our hypothesis, it is appropriate to review evidence that the limbic lobe is rich in centrally active peptides and their receptors, that the metabolism of such peptides is abnormal during severe stress, and that the release of such peptides locally within the limbic lobe may trigger abnormal discharge of limbic lobe neurons during stress. In the interest of 
clarity, we will emphasize results obtained for the peptide hormones termed endorphins because these compounds have been particularly well studied. However, many other peptide neurotransmitters and neuromodulators have recently been identified in the central nervous system (Barchas et al, 1978; Martin and Krieger, 1981), and might be expected to have altered metabolism during stress.

\section{Endorphins and Their Receptors in Limbic Lobe}

In the early 1970 s, several laboratories observed specific binding of radiolabelled narcotics and antagonists to brain membranes. In other words, they produced evidence that the brain, certain regions more than others, contains receptors specific for opiates (Kuhar et al, 1973; Way, 1979). This insight was followed in short order by isolation of the endogenous, naturally occurring substances that ordinarily interact with these receptors, in the absence of exogenously administered opiates. The first such substances to be isolated were termed enkephalins and proved to be peptides comprised of five amino acids each. Subsequent work has demonstrated that there is a second class of peptide hormones - sharing some structural features yet derived from a distinct precursor - that also interact with brain opiate receptors. The first class comprises not only the two enkephalin pentapeptides that were isolated first but also co-synthesized peptides including several of exceedingly high narcotic potency. The second class of compounds, termed endorphins, comprises a distinct group of peptides of which the most potent as a narcotic is the 31 amino acid peptide, beta-endorphin (B-EP). Other molecules synthesized from the same precursor as B-EP include adrenocorticotropic hormone (ACTH), melanocyte-stimulating hormones, and related fragments that bring about remarkable behavioral effects upon attention, learning, and memory (Morley et al, 1980), even in instances in which these related fragments possess little or no activity as narcotics (De Wied, 1981). (Current usage employs the term "endorphins" to refer to the peptides in both groups, but in this paper we shall not follow this convention.) The regional distribution within brain neurons of enkephalins differs somewhat from the distribution of endorphins, as might be expected for these two complementary, related, yet distinct systems (Rossier et al, 1977b; Watson et al, 1978). Receptors for enkephalins and endorphins are found in parallel to the concentrations of their endogenous ligands. It is clear that, particularly for the enkephalins but also for the endorphins, the structures that collectively comprise the limbic lobe - hypothalamus, hippocampus, septum, amygdala, portions of 
the cerebral cortex such as the temporal lobe, and the reticular formation of the midbrain (Martin et al, 1977) - are richly supplied with receptors for endogenous opioids as well as these compounds themselves. Again, a wealth of other evidence supports the view that opioid peptides are but two classes among many other peptide and amino acid neurotransmitters and neuromodulators that are present and that exert significant behavioral effects, within the central nervous system (Barchas et al, 1978; Martin and Krieger, 1981; Mühlethaler, Dreifuss and Gähwiler, 1982).

\section{Stress Effects on Endorphin Metabolism}

Recognition that ACTH and B-EP are synthesized together as parts of a larger, common precursor immediately prompted researchers to test whether the release of ACTH into blood during stress was paralleled by a release of beta-endorphin, and a variety of laboratories working independently promptly confirmed that this is so (Guillemin et al, 1977; Nakao et al, 1978). This result is important because ACTH release during stress has long been the subject of intensive study, and much if not all of the experimental results derived for ACTH may therefore be assumed to be true pari passu for B-EP. In particular, hypotension has been recognized to be a potent stimulus for ACTH secretion (Gann et al, 1978), and thus it was logical to presume that B-EP may also be released during hypotension. Were B-EP to act as does morphine to further lower blood pressure during hypovolemic shock, then administration of narcotic antagonists might be of benefit during shock. This hypothesis appears to be valid, in that administration of the narcotic antagonist naloxone during experimental and clinical hypovolemic shock has been associated with prompt elevation of systemic blood pressure and improved survival (Holaday and Faden, 1978; Faden and Holaday, 1979), and even prevention of stroke (Hosobuchi et al, 1982). Other stimuli known previously to evoke ACTH release, and recently shown to evoke B-EP release as well, include infection (Carr et al, 1982), hypoxemia (Wardlaw et al, 1979), hypoglycemia (Nakao et al, 1979), psychological stress (e.g., restraint or pain), electroshock therapy, exercise (Carr et al, 1981), and ether anesthesia. It is clear, therefore, that just as ACTH has long been recognized to be a stressresponsive hormone, so, too, is $\mathrm{B}-\mathrm{EP}$.

The peripheral actions of B-EP (other than producing hypotension) remain to be clarified, but the principal action of ACTH released into the blood is to cause release of cortisol and other steroid hormones from the adrenal cortex (Martin et al, 1977). In this re- 
gard, early studies on plasma levels of adrenal steroid hormones are pertinent: plasma concentrations of such hormones were greatly elevated in patients studied shortly before their death, regardless of their underlying diagnoses (Perkoff et al, 1954). Indirectly, therefore, such studies provide evidence in support of pituitary-adrenal activation in the pre-terminal state.

For technical reasons relating to their rapid metabolic degradation, studies of circulating enkephalins have proceeded much more slowly. The principal site of release of enkephalins into the blood appears to be the adrenal medulla, and they appear to be co-secreted along with epinephrine and norepinephrine. Many studies have confirmed that plasma levels of the latter two compounds rise promptly during stress, so one would expect that the enkephalins will prove to do so as well. Recent preliminary findings provide support for this view (Boarder et al, 1982).

Complicating the analysis of stress effects on endorphin or enkephalin metabolism is the existence of distinct compartments in which these compounds are synthesized, stored, and released. Thus, brain levels of B-EP may fail to rise during stimuli that provoke release of B-EP into the blood (Rossier et al, 1977a), or to change after non-physiologic interventions such as removal of the pituitary (which causes a marked decline in blood levels) or after treatment with exogenous steroid hormones (which also results in a decline of blood levels). On the other hand, studies of the response of central B-EP levels, or levels of B-EP in cerebrospinal fluid (CSF) surrounding the brain, during profound physiologic stress such as sepsis or hypovolemia are only now forthcoming (Carr et al, 1982). Preliminary results from such studies indicate that CSF levels of B-EP may rise significantly during such stress, although the source of such elevations has not been pinpointed, and a reflow of this substance from blood into brain cannot yet be excluded. Analysis of simultaneous blood and CSF levels of vasopressin, another centrally active pituitary hormone, during experimental hemorrhage has shown that while blood levels rise promptly and markedly, CSF levels also rise significantly, though more slowly (Wang et al, 1981). The source of the CSF vasopressin in that study was shown to be the brain, rather than reflow from plasma. Increased central opioid activity during stress is further indicated by a host of studies of other pituitary hormones such as prolactin and luteinizing hormone, whose secretion is modulated by endorphin and enkephalin within the brain, and also by many separate demonstrations that stress-induced analgesia is at least partially reversed by narcotic antagonists. 
It should be kept in mind when analyzing the behavior of central levels of B-EP during stress, and the relationship between central and peripheral levels of this hormone, that the blood-brain barrier opens in many instances of stress. Therefore, even negative studies showing that peripherally administered synthetic B-EP does not enter brain or CSF must be viewed as preliminary in that such studies are, as a rule, carried out in unstressed subjects and hence in conditions of maximum integrity of the blood-brain barrier.

Apart from the above considerations, there is an overwhelming consensus that the secretion of pituitary peptides occurs in response to the secretion of releasing factors by the brain, and the delivery of these factors down the portal vessels leading to the pituitary. Therefore, in circumstances of abnormally intense secretion of pituitary hormones, it is probable that brain production and/or release of releasing factors is itself abnormal. Well-documented evidence exists that releasing factors per se may influence the discharge of central neurons, and also that anatomical pathways exist by which pituitary hormones may be transported "retrograde" up the pituitary stalk into the brain (Bergland and Page, 1978).

To summarize: a firm consensus now exists that peripheral secretion of B-EP and the enkephalins is augmented during stress, and the likelihood is strong that concurrent disruptions of central endorphin and enkephalin metabolism also occur during the sorts of trauma and illness in which NDEs arise. It is reasonable to suppose that parallel changes occur as well in the metabolism of a variety of other less well-studied neurohormones.

\section{Endorphin Actions on Limbic Neurons}

It has long been appreciated that a side effect of morphine is to lower the seizure threshold (Urca et al, 1977; Frenk et al, 1978b). Characterization of enkephalins and endorphins has been followed by many studies of their electrophysiologic actions (Gahwiler and Herrling, 1981; Lewis et al, 1981). Enkephalins, when applied to many brain areas, suppress neuronal discharge, but within the hippocampus, enkephalins appear to inhibit discharge of interneurons, which are themselves inhibitory (Lee et al, 1980; Nicoll et al, 1977 and 1980). That is, the microinjection of enkephalins or analogs induces localized seizure activity by causing a release of normally present inhibition (Frenk et al, 1978a; Zieglgansberger et al, 1979; Dunwiddie et al, 1980; Gahwiler, 1980; Haas and Ryall, 1980). As for the endorphins, preliminary observations of rats given intracerebral injections of B-EP suggested that the animals were rendered 
catatonic, because they adopted a posture of waxy rigidity such that they would remain motionless even when stretched between two bookends. When electroencephalograms were obtained, it was at once apparent that the animals were experiencing intense limbic lobe neuronal hyperactivity without obvious signs of convulsion (Bloom et al, 1978; Henriksen et al, 1978). In related studies, anticonvulsant medications used to treat petit mal epilepsy were effective in blocking seizures induced by the application of enkephalins to the rat brain, but agents used in cases of grand mal epilepsy were not, suggesting a specific role for enkephalins in the pathogenesis of petit mal epilepsy (Snead and Bearden, 1980). Clinical studies have of course been much more limited, but even in patients with cancer pain given B-EP directly into CSF, analgesia and mood elevation may occur without pupillary construction or other peripheral signs of opiate action (Foley et al, 1979; Oyama et al, 1979).

Endorphins in the Pathogenesis of NDEs

Several researchers have considered the possibility that endorphins may figure in the genesis of NDEs (Lindley et al, 1981; Ring, 1980; Sabom, 1982). Each has viewed the actions of endorphins as simply equivalent to those of morphine, i.e., as potentially responsible for passivity and analgesia, but inadequate to explain the other psychological responses that in aggregate constitute "classical" NDEs. It should be apparent from the above that at least in theory, the vulnerability of limbic lobe neurons to alterations in endorphin and enkephalin metabolism, together with the disruption of the central secretion of these compounds during agonal states, provides a novel, unified, and (to a degree) testable basis for explaining the limbic lobe activation that appears to be a constant feature of NDEs (Carr and Gullo, 1980; Carr, 1981). In other words, I am proposing to assign to certain behaviorally active peptides an operational role as "endogenous hallucinogens" in agonal states.

This hypothesis may be tested experimentally. In fact, the emergence of characteristic electroencephalographic (EEG) patterns is already recognized to be a valuable prognostic marker of irreversibility in animal models of hemorrhagic shock (Baldwin and Bell, 1963; Fink et al, 1970; Kovach and Sandor, 1976). Clearly it will be necessary to correlate simultaneous EEGs and blood and CSF levels of opioid and other peptides in accepted models of resuscitation. Valuable evidence favoring the present hypothesis could also derive from single-unit recordings of hippocampal neurons in animal models of shock. Crude and indirect, but more clinically relevant evidence in 
favor of our hypothesis could derive from a finding of elevated (rather than reduced) levels of centrally active peptides in fresh postmortem brain tissues. Preliminary animal studies have actually provided evidence for the surprising result that brain levels of such neurohormones rise agonally (Ratter et al, 1981).

The present hypothesis may if nothing else explain a curious feature of the epidemiology of NDEs, in that they are less likely to occur under circumstances involving damage to brain structures (e.g., strokes or brain tumors) than during illnesses in which patients retain structurally intact neo-, allo-, and sub-cortical structures (Osis and Haraldsson, 1977; Drab, 1981; Lindley et al, 1981). Presumably, the occurrence of NDEs requires hyperactivity of an intact limbic lobe, followed by elaboration of this activity by a structurally intact cerebral cortex, events that parallel the generation of complex hallucinations during electrical stimulation of the hippocampus. That this highly organized sequence of events should be termed "dysfunction" is perhaps a misnomer, but the meaning (i.e., an unusual mode of function) is clear.

In conclusion, several cautionary notes are in order. First, I cannot agree that any clinical interventions based on this or other hypotheses should even be considered in the terminally ill, as others have suggested (Lindley et al, 1981). In some patients, administration of narcotic antagonists may be indicated as treatment for refractory shock (Dirksen et al, 1980), and health professionals in attendance may of course note the outcome, but in the absence of pressing medical indications, it would be unethical to interfere with the dignity and comfort of the terminally ill, and any studies having the potential to do so ought strongly to be discouraged. Second, results based on animal models in which narcotic antagonists are administered ought to be interpreted with caution, in view of recent findings that stress-induced endorphin secretion (at least into the periphery) is not blocked but instead is augmented by this maneuver (Carr et al, 1981b). Moreover, the outcome of administering systemic naloxone in an effort to study what occurs in circumscribed brain regions is likely to be inconclusive, if recent studies in this manner of depressed or schizophrenic patients are any guide. For these reasons, direct measurements of brain and CSF peptide levels in animal models, rather than responses to naloxone, would be a more practical starting point. Third, the present description only has relevance to those aspects of NDEs that appear to reflect abnormal brain function (Rodin, 1980) but cannot pretend to explain all features of each recorded NDE, particularly those aspects that are outside the present 
scientific framework (e.g., ESP). Fourth, nothing in the above should be taken as implying an exclusive or even predominant role for endogenous opioids in the pathogenesis of NDEs. Such peptides were discussed at length simply because more is known at present about their electrophysiologic actions than those of other peptides, and also because of the likelihood that their central metabolism is disrupted at a relatively low threshold of stress in comparison to other neurohormones. However, when one contemplates the hierarchical collapse (Thom, 1975) of multiple inter- and intra-cellular regulatory systems that takes place during the death of higher organisms, it seems likely that mechanisms apart from those outlined above also contribute to abnormal brain function. For example, nerve cell membranes may be depolarized by the opening of ion channels independent of the action of opiates, and such channels may be dysfunctional in extremes of hypoxia (Rodin, 1981), ischemia, or acidosis. Inhibitory interneurons capable of suppressing the discharge of limbic neurons may also be vulnerable to metabolic insults such as hypoxia. Lastly, even if careful scientific studies establish beyond any doubt the physiological substrate of dying, they would still have no relevance to the philosophical meaning of death, or its religious aspects. This last point may be best illustrated by considering that, while studies of the mechanisms of birth have given rise to many advances in knowledge and therapy, metaphysical questions about the meaning of entering the world remain unanswerable by experimental science. Nevertheless, just as studies of the physiology of birth have led to novel methods of saving lives, so, too, the elucidation of previously unstudied reflexes of the moribund state may also permit new perspectives on brain function in near death (Kramer, 1963) or during extreme psychological stress (Bettelheim, 1979) and may possibly result in unsuspected means of enhancing life.

\section{ACKNOWLEDGEMENTS}

Dr. Daniel Carr is a Daland fellow of the American Philosophical Society. Support for the preparation of this manuscript was provided in part by NIH grant AM 07028-07. Stimulating discussions' with Dr. Stephen Gullo of the Foundation of Thanatology catalyzed the ideas expressed above. 


\section{REFERENCES}

Aries, P. The Hour of Our Death. New York: Knopf, 1981.

Baldwin, B. A., and Bell, F. R. The effect of temporary reduction in cephalic blood flow on the EEG of sheep and calf. EEG Clin. Neurophysiol., 1963, 15, 465-473.

Barchas, J. D., Akil, H., Elliott, G. R., Holman, R. B., and Watson,

S. J. Behavioral neurochemistry: neuroregulators and behavioral states. Science, 1978, 200, 964-973.

Bergland, R. M., and Page, R. B. Can the pituitary secrete directly to the brain? (Affirmative anatomical evidence). Endocrinology, 1978, 102, 1325-1338.

Bettelheim, B. Individual and mass behavior in extreme situations. In Bettelheim, B., Surviving and Other Essays. New York: Knopf, 1979.

Bloom, F. E., Rossier, J., Battenberg, E. L. F., Bayon, A., French, E., Henriksen, S. J., Siggins, G. R., Segal, D., Browne, R., Ling, N., and Guillemin, R. Beta-endorphin: cellular localization, electrophysiological, and behavioral effects. In E. Costa and M. Trabucchi (Eds.), The Endorphins (Adv. Biochem. Psychopharmacol, Vol. 18). New York: Raven Press, 1978.

Boarder, M. R., Erdelyi, E., and Barchas, J. D. Opioid peptides in human plasma: evidence for multiple forms. J. Clin. Endocrinol. Metab., 1982, 54, 715-720.

Carr, D. B. Endorphins at the approach of death. Lancet, 1981, 1, 390.

Carr, D. B., and Gullo, S. V. Psychological responses in the dying patient - a role for behaviorally active peptide hormones? Archs. Fdn. Thanatology, $1980,8,82$.

Carr, D. B., Bullen, B. A., Skrinar, G. S., Arnold, M. A., Rosenblatt, M., Beitins, I. Z., Martin, J. B., and McArthur, J. W. Physical conditioning facilitates the exercise-induced secretion of beta-endorphin and beta-lipotropin in women. New Engl. J. Med., 1981, 305, 560-563.

Carr, D. B., Hamilton, A., Blume, H., Kasting, N., Arnold, M., Bergland, R., and Martin, J. Endotoxin-induced endorphin secretion: evidence in vivo for two secretory pools and feedback control. The Endocrine Society, 64th Annual Meeting, San Francisco, 1982.

De Wied, D. Pituitary neuropeptides and behavior. In K. Fuxe, T. Hokfelt, and R. Luft (Eds.), Central Regulation of the Endocrine System (Nobel Symposium 42). New York: Plenum Press, 1979. 
Dirksen, R., Otten, M. H., Wood, G. J., Verbaan, C. J., Haalebos, M. M. P., Verdouw, P. V., and Nijhhuis, G. M. M. Naloxone in shock. Lancet, 1980, 2, 1360-1361.

Drab, K. J. The tunnel experience: reality or hallucination? Anabiosis, 1981, 1, 126-152.

Dunwiddie, T., Mueller, A., Palmer, M., Stewart, J., and Hoffer, B. Electrophysiological interaction of enkephalins with neuronal circuitry in the rat hippocampus, I. Effects on pyramidal cell activity. Brain Research, 1980, 184, 311-330.

Faden, A. I., and Holaday, J. W. Opiate antagonists: a role in the treatment of hypovolemic shock. Science, 1979, 205, 317-318.

Fink, R. A., Burham, W. A., Owen, T. L., Dixon, A. C., and Goldstein, J. D. Hemorrhagic shock: the role of the central nervous system in fatality or survival. Neurology, 1970, 20, 408.

Foley, K. M., Kourides, I. A., Inturissi, C. E., Kaiko, R. F., Zaroulis, C. G., Posner, J. B., Houde, R. W., and Li, C. H. Beta-endorphin: analgesic and hormonal effects in humans. Proc. Natl. Acad. Sci. U.S.A., 1979, 76, 5377-5381.

Frenk, H., McCarty, B. C., and Liebeskind, J. C. Different brain areas mediate the analgesic and epileptic properties of enkephalin. Science, 1978a, 200, 335-337.

Frenk, H., Urca, G., and Liebeskind, J. C. Epileptic properties of leucine- and methionine-enkephalin: comparison with morphine and reversibility by naloxone. Brain Research, 1978b, 147, 327-337.

Gahwiler, B. H. Excitatory action of opioid peptides and opiates on cultured hippocampal pyramidal cells. Brain Research, 1980, 194, 193-203.

Gahwiler, B. H., and Herrling, P. L. Effects of opioid peptides on synaptic potentials in explants of rat hippocampus. Regulatory Peptides, 1981, 1, 317-326.

Gann, D. S., Ward, D. G., and Carlson, D. E. Neural control of ACTH: a homeostatic reflex. Rec. Prog. Horm. Res., 1978, 34, $357-400$.

Guillemin, R., Vargo, T., Rossier, J., Minick, S., Ling, N., Rivier, C., Bloom, F., and Vale, W. Beta-endorphin and adrenocorticotropin are secreted simultaneously by the pituitary gland. Science, 1977, 197, 1367-1369.

Haas, H. L., and Ryall, R. W. Presynaptic facilitation by enkephalin in the hippocampus. J. Physiol., 1980, 301, 37P-38P.

Hare, E. H. A short note on pseudo-hallucinations. Brit. J. Psychiat., 1973, 469-476. 
Henriksen, S., Bloom, F. E., McCoy, F., Ling, N., and Guillemin, R. Beta-endorphin produces non-convulsive limbic lobe seizures. Proc. Natl. Acad. U.S.A., 1978, 75, 5221-5225.

Holaday, J. W., and Faden, A. I. Naloxone reversal of endotoxin hypotension suggests role of endorphins in shock. Nature, 1978, $275,450-451$.

Hosobuchi, Y., Baskin, D. S., and Woo, S. K. Reversal of induced ischemic neurologic deficit in gerbils by the opiate antagonist naloxone. Science, 1982, 215, 69-71.

Keup, W. (Ed.). Origin and Mechanisms of Hallucinations. New York: Plenum Press, 1970.

Kovach, A. G. B., and Sandor, P. Cerebral blood flow and brain function during hypotension and shock. Ann. Rev. Physiol., 1976, 38, 571-596.

Kramer, W. From reanimation to deanimation. Acta Neurol. Scand., 1963, 39, 139-153.

Krieger, D. T., and Martin, J. B. Brain peptides. New Engl. J. Med., $1981,304,876-885$ and $944-951$.

Kuhar, M. J., Pert, C. B., and Snyder, S. H. Regional distribution of opiate receptor binding in monkey and human brain. Nature, $1973,245,447-450$.

Lee, H. K., Dunwiddie, T., and Hoffer, B. Electrophysiological interactions of enkephalins with neuronal circuitry in the rat hippocampus, II. Effects on interneuron excitability. Brain Research, $1980,184,331-342$.

Lewis, J. W., Caldecott-Hazard, S., Cannon, J. T., and Liebeskind, J. C. Possible role of opioid peptides in pain inhibition and seizures. In J. B. Martin, S. Reichlin, and K. Bick (Eds.), Neurosecretion and Brain Peptides. New York: Raven, 1981.

Lindley, J. H., Bryan, S., and Conley, B. Near-death experiences in a Pacific Northwest American population: The Evergreen Study. Anabiosis, 1981, 1, 104-124.

Martin, J. B., and Krieger, D. T. Brain peptides. New Engl. J. Med., $1981,304,876-885$ and $944-951$.

Martin, J. B., Reichlin, S., and Brown, G. M. Clinical Neuroendocrinology. Philadelphia: Davis, 1977.

Meduna, L. J. Carbon Dioxide Therapy. Springfield, Ill.: C. C. Thomas, 1950.

Merritt, H. H. A Textbook of Neurology, Fifth Edition. Philadelphia:

Lea and Feibiger, 1973.

Moody, R. A. Life After Life. New York: Bantam, 1975. 
Morley, J. E., Baranetzky, N. G., Wingert, T. D., Carlson, H. E., Hershman, J. M., Melmed, S., Levin, S. R., Jamison, K. R., Weitzman, R., Chang, R. J., and Varner, A. A. Endocrine effects of naloxone-induced opiate receptor blockade. J. Clin. Endocrinol. Metab., 1980, 50, 251-257.

Mühlethaler, M., Dreifuss, J. J., and Gähwiler, B. H. Vasopressin excited hippocampal neurones. Nature, 1982, 296, 749-751.

Nakao, K., Nakai, Y., Oki, S., Horii, K., and Imura, H. Presence of an immunoreactive beta-endorphin in human plasma: a concomitant release of beta-endorphin with adrenocorticotropin after metyrapone administration. J. Clin. Invest., 1978, 62, 1.395-1398.

Nakao, K., Nakai, Y., Jingami, H., Oki, S., Fukata, J., and Imura, H. Substantial rise of plasma beta-endorphin levels after insulininduced hypoglycemia in human subjects. J. Clin. Endocrinol. Metab., 1979, 49, 838-841.

Nicoll, R. A., Alger, B. E., and Jahr, C. E. Enkephalin blocks inhibitory pathways in the vertebrate CNS. Nature, 1980, 287, 22-25.

Nicoll, R. A., Siggins, G. R., Ling, N., Bloom, F. E., and Guillemin, R. Neuronal actions of endorphins and enkephalins among brain regions: a comparative microiontophoretic study. Proc. Natl. Acad. Sci. U.S.A., 1977, 74, 2584-2588.

Noyes, R., Jr., and Kletti, R. Depersonalization in the face of lifethreatening danger: an interpretation. Omega, 1976, 7, 103-114.

Osis, K., and Haraldsson, E. At the Hour of Death. New York: Avon, 1977.

Oyama, T., Jin, T., Yamaya, R., Ling, N., and Guillemin, R. Profound analgesic effects of beta-endorphin in man. Lancet, 1980, $1,122-124$.

Penfield, W., and Perot, P. The brain's record of auditory and visual experience. Brain, 1963, 86, 596-695.

Perkoff, G. T., Sandberg, A. A., Nelson, D. H., and Tyler, F. H. Clinical usefulness of determination of circulating 17-hydroxycorticosteroid levels. JAMA, 1954, 93, 1-8.

Ratter, S. J., Corder, R., Emson, P., Rosser, M., Tomlin, S., and Rees, L. H. Stability of pro-opiocortin related peptides in post mortem mouse brain tissue. The Endocrine Society, 63rd Annual Meeting, Cincinnati, 1981, 400.

Ring, K. Life at Death. New York: Coward, McCann and Geoghegan, 1980.

Ring, K. Near-Death Studies: A New Area of Consciousness Research. Storrs, Connecticut: International Association for NearDeath Studies, Inc., 1982. 
Rodin, E. A. The reality of near-death experiences: a personal perspective. J. Nerv. Ment. Dis., 1980, 168, 259-263.

Rodin, E. A. The reality of death experiences: a reply to commentaries. Anabiosis Newsletter, Feb., 1981, 15-16.

Rossier, J., French, E., Rivier, C., Ling, N., Guillemin, R., and Bloom, F. Foot-shock induced stress increased beta-endorphin in rat blood but not brain. Nature, 1977a, 270, 618-620.

Rossier, J., Vargo, T. M., Minick, S., Ling, N., Bloom, F. E., and Guillemin, R. Regional dissociation of beta-endorphin and enkephalin contents in rat brain and pituitary. Proc. Natl. Acad. Sci. U.S.A., 1977b, 74, 5162-5165.

Sabom, M. B. Recollections of Death: A Medical Perspective. New York: Harper and Row, 1982.

Siegel, R. K. Accounting for 'afterlife' experiences. Psychology Today, January 1981, 65-75.

Siegel, R. K., and West, L. J. (Eds.). Hallucinations: Behavior, Experience, and Theory. New York: Wiley and Sons, 1975.

Snead, O. C. III, and Bearden, L. J. Anticonvulsants specific for petit mal antagonize epileptogenic effect of leucine enkephalin. Science, $1980,210,1031-1033$.

Stevenson, I., and Greyson, B. Near-death experiences: relevance to the question of survival after death. JAMA, 1979, 242, 265-267.

Thom, R. Structural Stability and Morphogenesis (D. H. Fowler, trans.). Reading, Ma.: Benjamin/Cummings, 1975.

Trimble, M. R. Visual and auditory hallucinations. Trends in Neuroscience, 1981, 4, pp. I-IV.

Urca, G., Frenk, H., Liebeskind, J. C., and Taylor, A. N. Morphine and enkephalin: analgesic and epileptic properties. Science, 1977, 197, 83-86.

Wang, B. C., Share, L. Crofton, J. T., and Kimura, T. Changes in vasopressin concentration in plasma and cerebrospinal fluid in response to hemorrhage in anesthetized dogs. Neuroendocrinology, 1981, 33, 61-66.

Wardlaw, S. L., Stark, R., Baxi, L., and Frantz, A. G. Plasma betaendorphin and beta-lipotropin in the human fetus and delivery: correlation with arterial $\mathrm{pH}$ and $\mathrm{p}_{2}$. J. Clin. Endocrinol. Metab., $1979,49,888-891$.

Watson, S. J., Akil, H., Barchas, J. D. Evidence for two separate opiate peptide neural pathways. Nature, 1978, 275, 226-228.

Way, E. L. Review and overview of four decades of opiate research. In H. H. Loh and D. H. Ross (Eds.), Neurochemical Mechanisms of Opiates and Endorphins (Adv. Biochem. Psychopharmacol., Vol. 20). New York: Raven Press, 1979. 
West, L. J. (Ed.). Hallucinations. New York: Grune and Stratton, 1962.

Zieglgansberger, W., French, E. D., Siggins, G. R., and Bloom, F. E. Opioid peptides may excite hippocampal pyramidal neurons by inhibiting adjacent inhibitory interneurons. Science, 1979, 205, 414-417.

Requests for reprints to:

Daniel Carr, M.D.

Massachusetts General Hospital

Boston, Massachusetts 02114 
